\title{
A Comparative Analysis of Cutting Electrocautery and Scalpel for Performing Cutaneous Incisions Over the Neck- A Prospective, Randomized, Single Blind Study
}

\author{
Gaurav A Thakare*, Nitin Bhola, Anchal Agarwal and Chinmay Ghavat \\ Department of Oral and Maxillofacial Surgery, Datta Meghe Institute of Medical \\ Sciences, India \\ *Corresponding Author: Gaurav A Thakare, Department of Oral and Maxillofacial \\ Surgery, Datta Meghe Institute of Medical Sciences, India.
}

Received: December 28, 2021

Published: February 11, 2022

(C) All rights are reserved by Gaurav A

Thakare., et al.

DOI: $10.31080 /$ ASDS.2022.06.1317

\begin{abstract}
Aim: The aim of the study was to assess the outcome of patients following use of scalpel and Cutting Electrocautery over Neck incisions in patients undergoing Neck Dissection.

Materials And Methods: A total of 80 patients undergoing Maxillofacial surgical procedures requiring Neck incisions were analyzed prospectively from Jan 2018 to May 2020 and divided into two groups using the Even-Odd randomization method. Patients requiring cutaneous neck incisions were divided into two groups, Group A comprised the patients in whom incisions were given using electrocautery, whereas, Group B comprised of patients in whom incisions were given using Scalpel. Incision time, Blood loss, Postoperative pain, healing of wound and cosmetic assessments of the scar were compared in both the groups.

Results: Our study found that there was statistically significant lesser blood loss (ml) in Group A, (Electrocautery) (5.17 \pm 0.33 ) as compared to Group B, (scalpel group) (10.94 \pm 0.59$)(p<0.001)$ and shorter incision time in Group A (Electrocautery) (3.14 \pm 0.25$)$ as compared to Group B (scalpel group) $(5.20 \pm 0.23)(p<0.001)$. There was no statistically significant difference between the groups in terms of Postoperative pain, healing of wound and cosmetic assessments of the scar between two groups.

Conclusion: Cutaneous incisions designed by the cutting electrocautery unit require less time and were found to be superior to scalpel in terms of minimizing blood loss during the incision design, whereas no statistically significant difference in healing, postoperative pain and cosmetic outcome was noted.
\end{abstract}

Keywords: Electrocautery; Scalpel; Scar; Neck incision; REEDA

\section{Introduction}

Oral Cancer is the sixth most common cancer worldwide. It accounts for about $4 \%$ of all cancer cases with nearly $2 \%$ of the deaths resulting from it [1,2]. The therapeutic management of this disease entails, Surgery being the first line of treatment for majority of the diagnosed cases, followed by Oncoradiation and Oncomedicine. Surgical treatment has three distinctive phases, the resection of tumor, management of regional lymph nodes and reconstruction of defect, all of which require incisions.

Scalpel knife is the most commonly available instrument used for incising the skin and tissues while performing surgical proce- dures. When properly used, the scalpel can perform miracles while its misuse can cause catastrophes. Hippocrates was the first to describe the surgical scalpel. He used the word 'macairion', derived from 'machaira', an old Lacedaemonian sword, which had a broad cutting blade on a single edge and a sharp, straight point. Therefore, even in Hippocrates' time, the shape of the scalpel was much the same as it is today.

William T. Bovie is considered the father of electrosurgery [3]. Goldwyn described three eras encompassing the development of the modern electrosurgical technology. Electrocautery may be either monopolar or bipolar. Monopolar electrocautery is one most 
commonly used, in this, the high frequency current from electrocautery machine is delivered to an active electrode held by the surgeon.

Electrocautery provide enhanced hemostasis by sealing off blood vessels before they are cut. They use heat energy to denature proteins, which leads to vascular tamponade and eventual hemostasis. Electrocautery involves current frequencies in the range of $400 \mathrm{KHz}$ to $10 \mathrm{MHz}$. Despite being beneficial in terms ofminimizing blood loss, there are potential distinct disadvantages of using heat energy in surgical wounds. Thermal dissipation into surrounding tissue may lead to collateral damage to vital structures, increased post-operative pain, delayed wound healing and poor cosmetic outcome [4].

The purpose of the present study was to explore in our clinical setting the efficacy of cutting electrocautery incisions versus scalpel incisions, particularly to see if they take a longer time to perform, blood loss, postoperative pain, healing of wound and cosmetic result, by assessing scar tissue in head and neck cancer patients.

\section{Material and Methods}

A prospective, randomized, single blind study was performed on 80 patients who met the inclusion criteria and were randomly divided into two groups based on Even-Odd randomization, with the Even numbered patients being allocated to.

\section{Group A (Experimental Group)}

Patients requiring Neck incisions as a part of the treatment protocol for whom the incisions (Figure 5) were given using Cutting electrocautery (Figure 2) and the odd numbered patients being allocated to.

\section{Group B (Control Group)}

Patients requiring Neck incisions as a part of the treatment protocol for whom the incisions (Figure 6) were given using Scalpel knife (Figure 1 and 2).

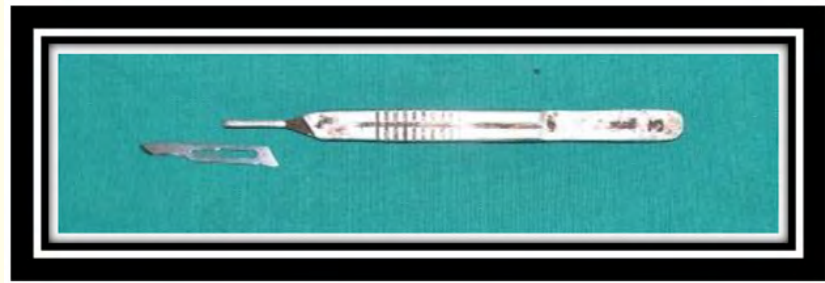

Figure 1: Scalpel.

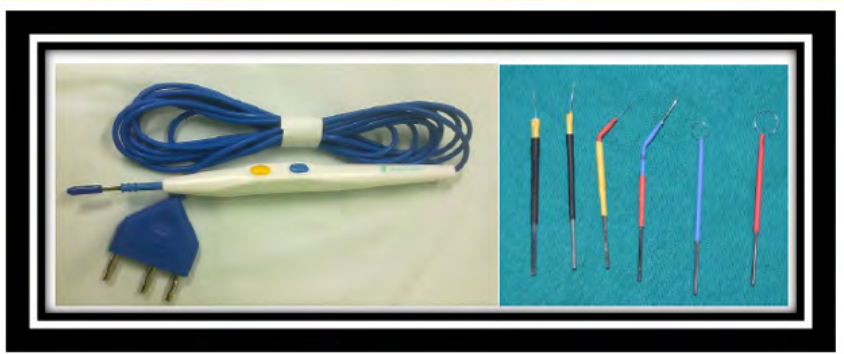

Figure 2: Electrocautry.

The purpose of the present study was explained to the patients and a written informed consent was obtained from all the participants. A detailed case history of the patient was recorded and a thorough clinical examination was carried out. The treatment protocol was decided and explained to the patient. The need for Incision and post operative pain and scar formation were explained to the patient. After obtaining pre-anesthetic fitness for the said surgical procedure under general anesthesia, the patient was posted for the procedure. All the cases were operated by a single senior surgeon having considerable experience in head and neck surgery. The side of the neck where the incision was planned was extended and incision was designed according to standard design of Apron's incision and marked using a surgical marker.

Adrenaline + Saline was infiltrated and after an interval of 7 minutes, incision was given.

For Group A patients, the dermis and the epidermis over the neck were incised using a cutting electrocautery.

For Group B patients, the dermis and the epidermis over the neck were incised using a Surgical scalpel or knife. The blade used for the Incision was a No. 15 Stainless steel blade

Only Pre-weighed sterile gauze piece were used to mop up the blood during incision.

The following parameters were then assessed:

Intra-operatively

Incision time

The incision time was calculated from the start of incision in the dermis up to exposure of the platysma muscle, with the aid of a stopwatch (Figure 3 and 4 ). 


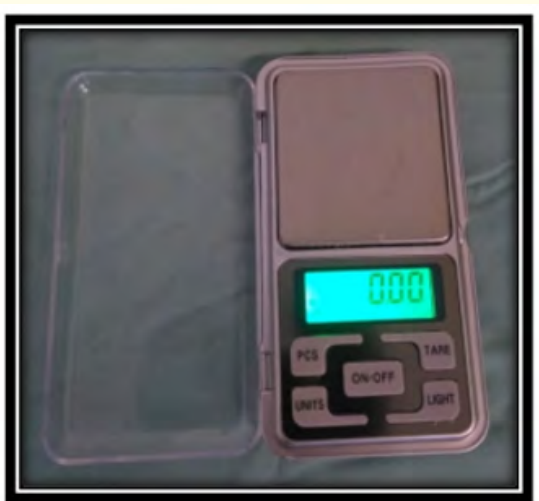

Figure 3: Weighing Machine.

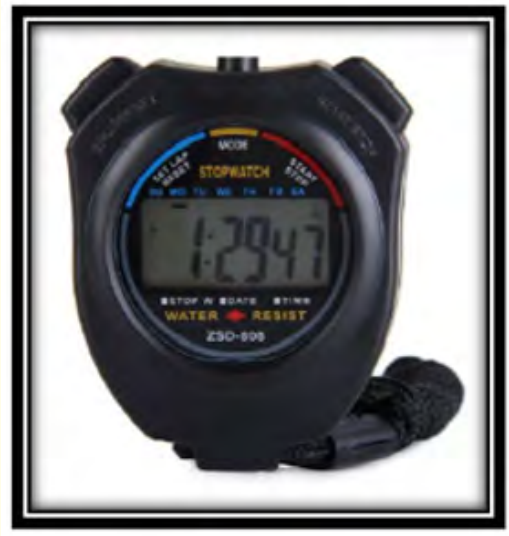

Figure 4: Stopwatch.

\section{Blood loss (BL)}

The blood loss incurred during the incision was calculated by the following method:

Weighing method [5]

The dry gauze was weighed on an electric weighing machine (fig.no.3) preoperatively under aseptic precautions and the weight was charted in grams (gm). Only these were taken to the surgical field for mopping.

Once the underlying superficial fascia was exposed, all the gauzes used were counted and weighed again. No bipolar or monopolar was used as a rescue hemostatic medium during neck incision performed using a surgical scalpel.
The difference in the weight was the blood loss during the neck dissection.

\section{Calculation}

Initial weight $=\mathrm{i}$ gm

Number of gauze used $=\mathrm{n}$

Final weight $=\mathrm{f}$ gm .

$B L=f-(n \times i)$.

According to Vitello., et al [6], the density of blood is similar to water and hence $1 \mathrm{gm}$ of blood can be calculated as $1 \mathrm{ml}$ of blood loss. Thus the amount of blood loss in gm acquired using the weighing method, is to be converted to ml using this principle.

At the end of the surgery, an antibiotic dressing was given over the sutured neck incision and the patient was kept on antibiotic therapy as is the protocol of the hospital for post surgical patients.

In the post operative period, following parameters were evaluated

\section{Post-operatively}

Post-operative pain [7]:

Post operative pain was evaluated by the Visual Analog Scale after 24 hours and on the $7^{\text {th }}$ post-operative day and the grading was noted.

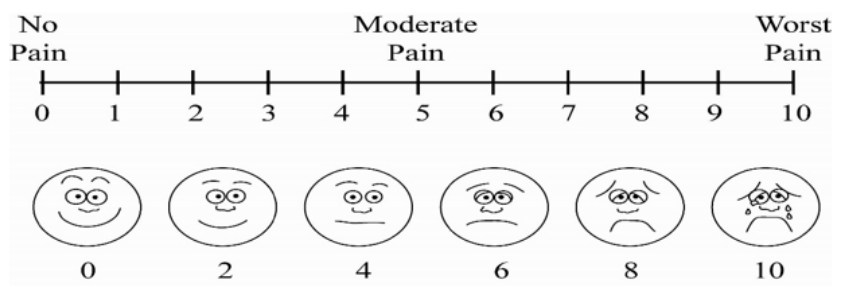

Figure A

Healing of the cutaneous incision [8]:

The cutaneous neck incision healing was assessed using a modification of the REEDA Scale which was given by Davidson. REEDA scale was developed by Davidson, to assess the healing of the perineural incisions following Episotomy procedure. We modified the 
existing scale, by keeping the parameters of Redness, Edema, Ecchymosis, Discharge and Approximation of the wound edges, to assess the healing of the cutaneous incisions given over the neck. The observer used a pre-sterilised $15 \mathrm{~cm}$ ruler with. $10 \mathrm{~cm}$ precision to assess and score the healing. In the upright position, with an ad- ditional light source, the ruler was placed perpendicular to the line of incision. The $3 \mathrm{~cm}$ marking on the ruler was taken as the reference point and placed on the incision. In this manner, the redness, edema and ecchymosis on either side of the cutaneous incision was measured precisely.

\begin{tabular}{|c|c|c|c|c|c|}
\hline Points & Redness & Edema & Ecchymosis & Discharge & Approximation \\
\hline $\mathbf{0}$ & None & None & None & None & Closed \\
\hline 1 & $\begin{array}{l}\text { Within } .25 \\
\text { cm of incision } \\
\text { bilaterally }\end{array}$ & $\begin{array}{l}\text { Peri-incisional, } \\
\text { less than } 1 \mathrm{~cm} \\
\text { from incision }\end{array}$ & $\begin{array}{c}\text { Within } .25 \mathrm{~cm} \\
\text { bilaterally or } .5 \mathrm{~cm} \\
\text { unilaterally }\end{array}$ & Serous & $\begin{array}{c}\text { Skin separation } 3 \mathrm{~mm} \text { or } \\
\text { less }\end{array}$ \\
\hline 2 & $\begin{array}{l}\text { Within } .5 \mathrm{~cm} \\
\text { of incision } \\
\text { bilaterally }\end{array}$ & $\begin{array}{l}\text { Peri-incisional, } \\
\text { between } 1 \text { to } 2 \\
\text { cm from inci- } \\
\text { sion }\end{array}$ & $\begin{array}{l}\text { Between } .25 \text { to } 1 \\
\mathrm{~cm} \text { bilaterally or } \\
\text { between } .5 \text { to } 2 \mathrm{~cm} \\
\text { unilaterally }\end{array}$ & Serosanguinous & $\begin{array}{l}\text { Skin and subcutaneous fat } \\
\text { separation }\end{array}$ \\
\hline 3 & $\begin{array}{l}\text { Beyond } .5 \mathrm{~cm} \\
\text { of incision } \\
\text { bilaterally }\end{array}$ & $\begin{array}{l}\text { Peri-incisional, } \\
\text { greater than } 2 \\
\text { cm from inci- } \\
\text { sion }\end{array}$ & $\begin{array}{l}\text { Greater than } 1 \mathrm{~cm} \\
\text { bilaterally, or } 2 \mathrm{~cm} \\
\text { unilaterally }\end{array}$ & Bloody, purulent & $\begin{array}{l}\text { Skin, subcutaneous fat and } \\
\text { fascial layer separation }\end{array}$ \\
\hline Score & & & & & \\
\hline
\end{tabular}

Table A: Total:

\section{Score:}

\section{0-2 - Optimal Healing \\ 3-9 - Suboptimal Healing \\ 10-15 - Compromised healing.}

\section{Scar formation [9]:}

Scar formation over neck incision after suture removal was evaluated by both the Observer and the patient using a Patient and Observer Scar Assessment Scale (POSAS) and the values were recorded on follow-up visit of 3 months post discharge from the hospital.
It consists of two numerical scales: The patient Scar Assessment Scale and Observer Scar Assessment Scale. It assesses vascularity, pigmentation, thickness, relief, pliability and surface area and it incorporates patient assessments of pain, itching, colour, stiffness, thickness and relief.

\begin{tabular}{|c|c|c|c|c|c|c|c|c|c|c|}
\hline \multirow{2}{*}{ Observer component* } & \multicolumn{5}{|c|}{ Normal skin } & \multicolumn{5}{|c|}{ Worst scar imaginable } \\
\hline & 1 & 2 & 3 & 4 & 5 & 6 & 7 & 8 & 9 & 10 \\
\hline $\begin{array}{l}\text { Vascularity } \\
\text { Pigmentation } \\
\text { Thickness } \\
\text { Relief } \\
\text { Pliability } \\
\text { Surface area } \\
\text { Overall opinion }\end{array}$ & $\begin{array}{l}0 \\
0 \\
0 \\
0 \\
0 \\
0 \\
0 \\
0\end{array}$ & $\begin{array}{l}\circ \\
\circ \\
\circ \\
\circ \\
\circ \\
0 \\
0 \\
0\end{array}$ & $\begin{array}{l}0 \\
0 \\
0 \\
0 \\
0 \\
0 \\
0\end{array}$ & $\begin{array}{l}0 \\
0 \\
0 \\
0 \\
0 \\
0 \\
0\end{array}$ & $\begin{array}{l}0 \\
\circ \\
\circ \\
0 \\
0 \\
0 \\
0\end{array}$ & $\begin{array}{l}\circ \\
\circ \\
\circ \\
\circ \\
\circ \\
\circ \\
0 \\
0\end{array}$ & $\begin{array}{l}0 \\
\circ \\
\circ \\
0 \\
0 \\
0 \\
0\end{array}$ & $\begin{array}{l}0 \\
\circ \\
\circ \\
0 \\
0 \\
0 \\
0 \\
0\end{array}$ & $\begin{array}{l}0 \\
0 \\
0 \\
0 \\
0 \\
0 \\
0 \\
0\end{array}$ & $\begin{array}{l}0 \\
0 \\
0 \\
0 \\
0 \\
0 \\
0 \\
0 \\
0\end{array}$ \\
\hline \multirow{2}{*}{ Patient component } & \multicolumn{5}{|c|}{ No } & \multicolumn{5}{|c|}{ Yes } \\
\hline & 1 & 2 & 3 & 4 & 5 & 6 & 7 & 8 & 9 & 10 \\
\hline $\begin{array}{l}\text { Is the scar painful? } \\
\text { Is the scar itching? } \\
\text { Is the color of the scar different? } \\
\text { Is the scar more stiff? } \\
\text { Is the thickness of the scar different? } \\
\text { Is the scar irregular? } \\
\text { Overall opinion }\end{array}$ & $\begin{array}{l}0 \\
\circ \\
0 \\
0 \\
0 \\
0 \\
0 \\
0\end{array}$ & $\begin{array}{l}\circ \\
\circ \\
\circ \\
\circ \\
\circ \\
\circ \\
0 \\
0\end{array}$ & $\begin{array}{l}0 \\
0 \\
0 \\
0 \\
0 \\
0 \\
0\end{array}$ & $\begin{array}{l}0 \\
0 \\
0 \\
0 \\
0 \\
0 \\
0\end{array}$ & $\begin{array}{l}\circ \\
\circ \\
\circ \\
0 \\
0 \\
0 \\
0\end{array}$ & $\begin{array}{l}0 \\
0 \\
0 \\
0 \\
0 \\
0 \\
0 \\
0\end{array}$ & $\begin{array}{l}0 \\
0 \\
0 \\
0 \\
0 \\
0 \\
0\end{array}$ & $\begin{array}{l}0 \\
0 \\
0 \\
0 \\
0 \\
0 \\
0 \\
0\end{array}$ & $\begin{array}{l}0 \\
0 \\
0 \\
0 \\
0 \\
0 \\
0 \\
0\end{array}$ & $\begin{array}{l}0 \\
0 \\
0 \\
0 \\
0 \\
0 \\
0\end{array}$ \\
\hline
\end{tabular}

-In observer component, all parameters consisted of additional category: Vascularity: pale, pink, red, purple or mix; Pigmentation: hypopigmentaion, hyperpigmentaion or mix; Thickness: thicker or thinner; Relief: more, less or mix; Pliability: supple, stiff or mix Surface area: expansion, contraction or mix

Figure B: Score: 7-21 - Normal skin (Absence of visible scar )

\section{2-42 - Inconspicuous scar}

43-70 - Visible scar. 
A Comparative Analysis of Cutting Electrocautery and Scalpel for Performing Cutaneous Incisions Over the Neck - A Prospective, Randomized, Single Blind Study

\section{Results}

The mean age of electrocautery group was $51.82 \pm 12.13$ years and the mean age of scalpel group was $50.70 \pm 10.36$ years.A total of $61(76.3 \%)$ males and 19 (22.5\%) females participated in the study. There were 33 (82.5\%) males and 7 (17.5\%) females in electrocautery group and $28(70.0 \%)$ males and 12 (30.0\%) females in scalpel group.

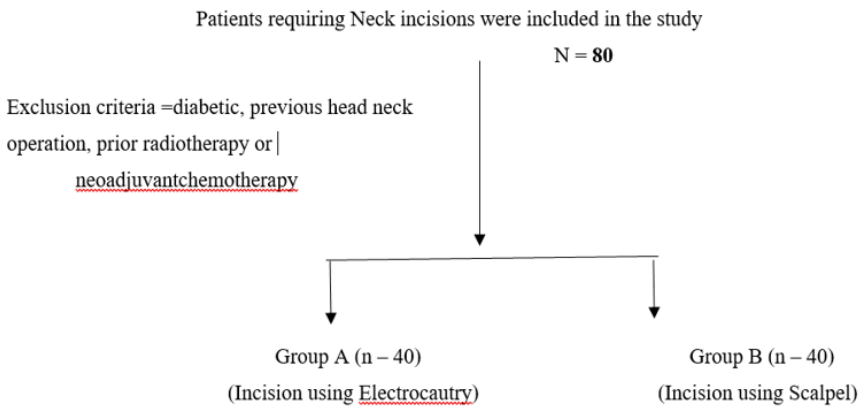

\section{Outcomes measured}

- Total time taken in performing Incision

- Mean blood loss while making skin incision

- $\quad$ Postoperative Pain

- Wound healing

- $\quad$ Cosmetic assessment of scar.

Incision time and blood loss while performing incision

The mean incision time (mins) was compared between electrocautery and scalpel group. It was found that there was statistically significant difference in mean incision time (mins) between electrocautery and scalpel group $(p<0.001)$. The mean incision time (mins) of electrocautery group $(3.14 \pm 0.25)$ was significantly lesser than the scalpel group (5.20 \pm 0.23 ) (Figure 5 to 7 ).

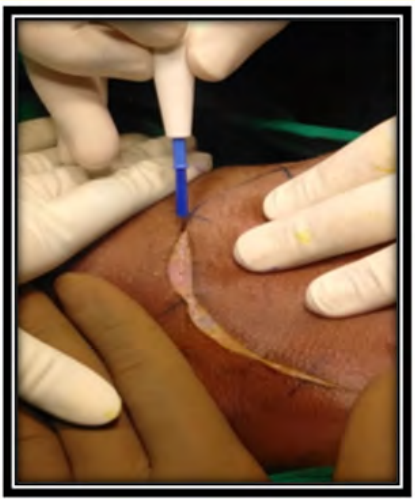

Figure 5: Incision using cutting Electrocautry.

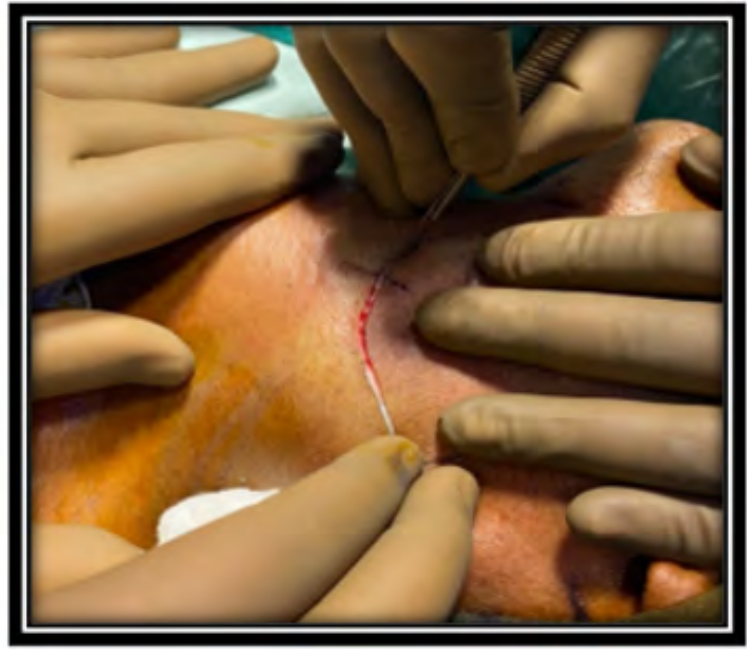

Figure 6: Incision using Scalpel.

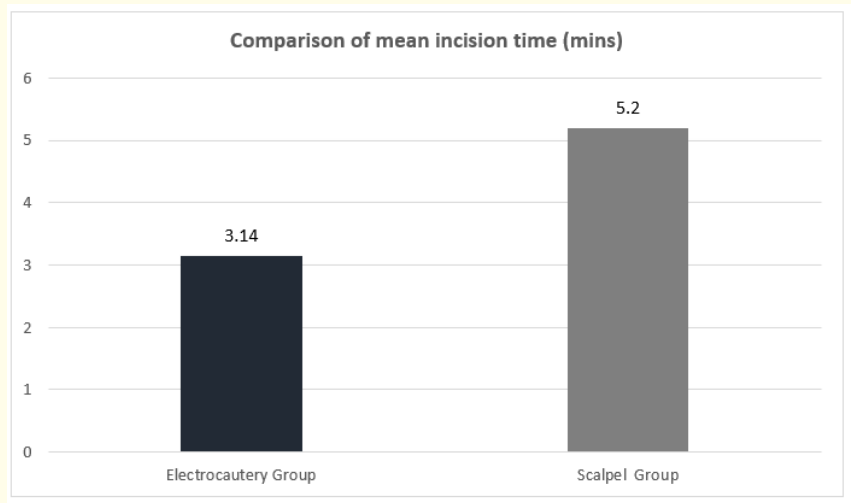

Figure 7: Comparison of mean incision time (mins) between electrocautery and scalpel group.

The mean blood loss (ml) was compared between electrocautery and scalpel group. It was found that there was statistically significant difference in mean blood loss ( $\mathrm{ml}$ ) between electrocautery and scalpel group ( $\mathrm{p}<0.001)$. The mean blood loss (ml) of electrocautery group $(5.17 \pm 0.33)$ was significantly lesser than the scalpel group (10.94 \pm 0.59 ) (Figure 8).

\section{Wound healing, postoperative pain and Scar assessment}

Notstatistically significant difference was noted in Post operative pain on the $1^{\text {st }}$ and $7^{\text {th }}$ post operative days in the Electrocautery group and Scalpel group. The Healing of the cutaneous incisions 


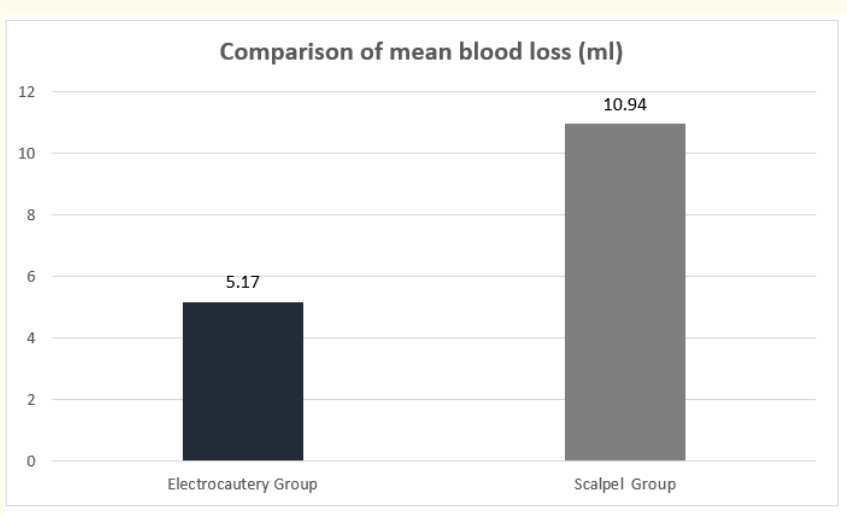

Figure 8: Comparison of mean blood loss (ml) between electrocautery and scalpel group.

was found to be similar in both the groups on Day 2, 5 and 7 as assessed using the modified REEDA scale. No significant distinction was observed in the cosmetic results between the scalpel and the electrocautery group.

\begin{tabular}{|l|c|c|c|c|c|c|}
\hline Group & N & Mean & S.D. & S.E. & M.D. & P-value $^{\#}$ \\
\hline Electrocautery & 40 & 3.14 & 0.25 & 0.04 & -2.06 & $<0.001^{\dagger}$ \\
\hline Scalpel & 40 & 5.20 & 0.23 & 0.03 & & \\
\hline
\end{tabular}

Table 1: Comparison of mean incision time (mins) between electrocautery and scalpel group.

\begin{tabular}{|l|c|c|c|c|c|c|}
\hline Group & N & Mean & S.D. & S.E. & M.D. & P-value $^{\#}$ \\
\hline Electrocautery & 40 & 5.17 & 0.33 & 0.05 & -5.77 & $<0.001^{\dagger}$ \\
\hline Scalpel & 40 & 10.94 & 0.59 & 0.09 & & \\
\hline
\end{tabular}

Table 2: Comparison of mean blood loss (ml) between electrocautery and scalpel group.

\section{Discussion}

Neck dissections require incisions to be placed over the skin of the neck which are often designed as per the needs and the preference of the surgeon.

The stainless steel scalpel knife, introduced in 1904, and later modified by Morgan Parker in 1915, is the most commonly available instrument for incising the cutaneous structures in an operative setting [10]. However, the scalpel use results in bleeding which obscures the operating field resulting in increased time required for the incision Scalpel use can also lead to collateral injury while being passed between a scrub nurse and the operating surgeon.

In the present study, 80 patients were included and randomized into two groups, with 40 patients included in the electrocautery group and 40 patients in the Scalpel group. The neck incisions were designed and given as per the need of the surgery by a single senior operating surgeon. The blood loss while giving the incision and the time required were calculated. Similarly, post operatively pain, healing of the cutaneous incisions was evaluated by a single observer in the post op period and closure was done by a single senior operating surgeon. A single observer evaluated the Scar formation at 3 month follow up period by Patient And Observer Scar Assessment Scale (POSAS) [9].

Of the 80 patients included in the present study, 33 were males and 7 were females in the Electrocautery group, where as in the scalpel group, 28 were males and 12 were females. The mean age of patients in the electrocautery group was $51.82 \pm 12.13$ years and in the scalpel group was $50.70 \pm 10.36$ years [12]

The incision time required was calculated from the start of the incision at the epidermis to the exposure of the platysma muscle. The mean incision time in the electrocautery group was $3.14 \pm 0.25$ mins and in the scalpel group was $5.20 \pm 0.23$ mins. The difference between the mean incision time in both the groups was compared and found to be statistically significant ( $\mathrm{p}<0.001)$. Kearns., et al. [11] reported electrocautery being superior in terms of time requirement for incising the tissues.

In the present study, the blood loss incurred during the incision was calculated by the weighing method using a pre weighed gauze and assuming $1 \mathrm{gm}$ is equal to $1 \mathrm{ml}$ of blood loss [6]. In the electrocautery group, the mean blood loss was $5.17 \pm 033 \mathrm{ml}$ and in the scalpel group was $10.94 \pm 0.59 \mathrm{ml}$. On comparing the means between both groups, it was found that the difference was statistically significant, with mean blood loss being lesser in the Electrocautery group than the Scalpel group. Chau., et al. [12-19] who found the blood loss to be less in the Electro cautery group than the Scalpel group in various skin incisions performed over the Head and Neck region. 
The Visual Analogue Scale was explained to the patient prior to the surgical procedure in detail [7]. Post operative pain was recorded on the VAS scale by the patient post operative day 1 , no statistically significant difference was noted between the two groups ( $p$ $=0.918$ ). Similarly, the VAS value was recorded on the $7^{\text {th }}$ postoperative day, the difference between the two was compared and was found to be not statistically significant ( $p=0.063$ ).

The healing of the cutaneous incisions performed by the two techniques was assessed using a modification of the REEDA scale given by Davidson. The scale comprises of 5 parameters of healing, viz., Redness, Edema, Ecchymosis, Discharge and Approximation. The scores for the scale are divided into subgroups, with 0 - 2 denoting Optimal healing, 3 - 9 - Suboptimal healing and $10-15$ - Compromised healing. A comparison of the means of two groups revealed no statistically significant difference $(p=0.785)$.

Similarly, On comparison the mean scores on Day 5 and 7 for the electrocautery group and Scalpel group, no significant difference in the mean modified REEDA score was noted in both the groups ( $\mathrm{p}=$ $0.958)(p=0.567)$.

In the present study, the scar formation was observed by the Observer and the patient at the 3 month follow up post operatively and was recorded on the Patient and Observer Scar Assessment Scale (POSAS). The scores for the scale are divided into subgroups, with 7 - 21 denoting Normal skin (Absence of visible scar), 22 - 42 Inconspicuous scar and 43 - 70 - Visible scar. Mean scar assessment score recorded by the observer in the electrocautery group and Scalpel group, when compared was found to be not statistically significant ( $p=0.190)$. Mean scar assessment score recorded by the patient in the electrocautery group and Scalpel group, when compared, the difference of the mean scores between the two groups was found to be No statistically significant $(p=0.206)$.

\section{Conclusion}

Cutaneous incisions designed by the electrocautery unit require less time and are superior in terms of minimizing blood loss during the incision design as compared to scalpel incision. Whereas no statistically significant difference was noted in terms of healing, post operative pain and cosmetic outcome between the two groups.

\section{Bibliography}

1. WHO Regional Office for the South-East Asia Region. Health Situation in the South-East Asia Region: 2001-2007.

2. Agarwal SP and Rao YN. "FIFTY YEARS OF CANCER CONTROL IN INDIA (2008).

3. Ochsner J. “Surgical Knife”. Texas Heart Institute Journal 36.5 (2009): 441-443.

4. Allan SN., et al. "A comparative study of scalpel and electrosurgical incision on subsequent wound healing". Journal of Pediatric Surgery 17.1 (1982): 52-54.

5. Chrysos E., et al. "A prospective study comparing diathermy and scalpel incisions in tension-free inguinal hernioplasty". The American Surgeon - SAGE Journals 71.4 (2005): 326-329.

6. Vitello DJ., et al. "Blood Density Is Nearly Equal to Water Density: A Validation Study of the Gravimetric Method of Measuring Intraoperative Blood Loss". Journal of Veterinary Science (2015).

7. Delgado DA., et al. "Validation of Digital Visual Analog Scale Pain Scoring With a Traditional Paper-based Visual Analog Scale in Adults". Journal of the American Academy of Orthopaedic Surgeons (2018).

8. Alvarenga MB., et al. "Episiotomy healing assessment: Redness, Oedema, Ecchymosis, Discharge, Approximation (REEDA) scale reliability1". Revista Latino-Americana de Enfermagem 23.1 (2015): 162-168.

9. Bianchi FA., et al. "Use of Patient and Observer Scar Assessment Scale for evaluation of facial scars treated with self-drying silicone gel”. Journal of Craniofacial Surgery 21.3 (2010): 719-723.

10. Ismail A., et al. "Cutting electrocautery versus scalpel for surgical incisions: a systematic review and meta-analysis". Journal of Surgical Research 220 (2017): 147-163.

11. Kearns SR., et al. "Randomized clinical trial of diathermy versus scalpel incision in elective midline laparotomy". British Journal of Surgery 88.1 (2001): 41-44.

12. Chau JKM., et al. "Steel scalpel versus electrocautery blade: comparison of cosmetic and patient satisfaction outcomes of different incision methods". Journal of Otolaryngology - Head and Neck Surgery 38.4 (2009): 427-433. 
13. Byrne FJ., et al. "Diathermy versus scalpel incisions for hemiarthroplasty for hip fracture: a randomised prospective trial". European Journal of Orthopaedic Surgery and Traumatology 17.5 (2007): 445-448.

14. Kumar V., et al. "A comparative study of scalpel and surgical diathermy incision in elective operations of head and neck cancer". Indian Journal of Cancer 48.2 (2011): 216-219.

15. Ly J., et al. "Systematic review and meta-analysis of cutting diathermy versus scalpel for skin incision". British Journal of Surgery 99 (2012): 613-620.

16. Shivagouda P., et al. "Prospective randomized control trial comparing the efficacy of diathermy incision versus scalpel incision over skin in patients undergoing inguinal hernia repair". The Recent Research in Science and Technology (2010).

17. Siraj A., et al. "Elective midline laparotomy: Comparison of Diathermy and scalpel incisions". The Professional Medical Journal 18 (2011): 106-111.

18. Hussain SA and Hussain S. "Incisions with knife or diathermy and postoperative pain". British Journal of Surgery 75.12 (1988): 1179-1180.

19. Pearlman NW., et al. "A prospective study of incisional time, blood loss, pain, and healing with carbon dioxide laser, scalpel, and electrosurgery". Archives of Surgery 126.8 (1991): 1018-1020.

\section{Assets from publication with us}

- Prompt Acknowledgement after receiving the article

- Thorough Double blinded peer review

- Rapid Publication

- Issue of Publication Certificate

- High visibility of your Published work

Website: www.actascientific.com/

Submit Article: www.actascientific.com/submission.php

Email us: editor@actascientific.com

Contact us: +919182824667 